\title{
Dominant features in three-dimensional turbulence structure: comparison of non-uniform accelerating and decelerating flows
}

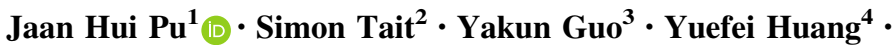 \\ Prashanth Reddy Hanmaiahgari ${ }^{5}$
}

Received: 5 March 2017/Accepted: 30 October 2017/Published online: 6 November 2017

(C) The Author(s) 2017. This article is an open access publication

\begin{abstract}
The results are presented from an experimental study to investigate three-dimensional turbulence structure profiles, including turbulence intensity and Reynolds stress, of different non-uniform open channel flows over smooth bed in subcritical flow regime. In the analysis, the uniform flow profiles have been used to compare with those of the nonuniform flows to investigate their time-averaged spatial flow turbulence structure characteristics. The measured non-uniform velocity profiles are used to verify the von Karman constant $\kappa$ and to estimate sets of log-law integration constant $B_{r}$ and wake parameter $\Pi$, where their findings are also compared with values from previous studies. From $\kappa, B_{r}$ and $\Pi$ findings, it has been found that the log-wake law can sufficiently represent the nonuniform flow in its non-modified form, and all $\kappa, B_{\mathrm{r}}$ and $\Pi$ follow universal rules for different bed roughness conditions. The non-uniform flow experiments also show that both
\end{abstract}

Jaan Hui Pu

j.h.pu1@bradford.ac.uk

Simon Tait

s.tait@sheffield.ac.uk

Yakun Guo

y.guo16@bradford.ac.uk

Yuefei Huang

yuefeihuang@tsinghua.edu.cn

Prashanth Reddy Hanmaiahgari

hpr@civil.iitkgp.ernet.in

1 School of Engineering, Faculty of Engineering and Informatics, University of Bradford, Bradford DB7 1DP, UK

2 Department of Civil and Structural Engineering, University of Sheffield, Sheffield S1 3JD, UK

3 School of Engineering, Faculty of Engineering and Informatics, University of Bradford, Bradford BD7 1DP, UK

4 State Key Laboratory of Hydro-Science and Engineering, Tsinghua University, Beijing 100084, China

5 Department of Civil Engineering, Indian Institute of Technology, Kharagpur 721302, India 
the turbulence intensity and Reynolds stress are governed well by exponential pressure gradient parameter $\beta$ equations. Their exponential constants are described by quadratic functions in the investigated $\beta$ range. Through this experimental study, it has been observed that the decelerating flow shows higher empirical constants, in both the turbulence intensity and Reynolds stress compared to the accelerating flow. The decelerating flow also has stronger dominance to determine the flow non-uniformity, because it presents higher Reynolds stress profile than uniform flow, whereas the accelerating flow does not.

Keywords Non-uniform flow $\cdot$ Accelerating flow $\cdot$ Decelerating flow $\cdot$ Uniform flow $\cdot$ Smooth bed $\cdot$ Turbulence intensity $\cdot$ Reynolds stress $\cdot$ Turbulence structure

\section{List of symbols}

$\mathrm{B}_{\mathrm{r}} \quad$ Log-law integration constant

$\mathrm{D}_{\mathrm{uw}}$ Empirical exponential constants for Reynolds stress profile

Fr Froude number

g Gravitational acceleration

h Water flow depth

$\mathrm{k}_{\mathrm{s}} \quad$ Nikuradse roughness

P Pressure

R Hydraulic radius

$\mathrm{Re}_{\mathrm{k}} \quad$ Roughness Reynolds number

$\mathrm{S}_{\mathrm{o}} \quad$ Channel slope

u Flow velocity

$\mathrm{u}_{*} \quad$ Shear velocity

$\mathrm{u}^{\prime} \quad$ Fluctuation of streamwise velocity

$\mathrm{v}^{\prime} \quad$ Fluctuation of lateral velocity

$\mathrm{w}^{\prime} \quad$ Fluctuation of vertical velocity

$\mathrm{x} \quad$ Longitudinal distance

y Lateral distance

z Vertical distance

$\mathrm{z}_{\mathrm{o}} \quad$ Reference zero-plane displacement level

$\beta \quad$ Pressure gradient parameter

$\delta \quad$ Water depth where maximum velocity occurs

$\kappa \quad$ Von Karman constant

$\lambda_{\text {uw }}$ Empirical exponential constant for Reynolds stress profile

$v \quad$ Kinematic viscosity

II Wake parameter

$\rho \quad$ Water density

$\tau_{\mathrm{o}} \quad$ Bed shear stress

\section{Introduction}

The analysis of flow turbulence is commonly performed on the time-averaged velocity, turbulence intensity and Reynolds stress in two-dimensional (2D) flow domain [19]. However, studying 3D flow characteristics can provide more descriptive flow information 
about its turbulence structure, which is useful for various hydraulic engineering applications. The time-averaged flow velocity is often reproduced by logarithmic profile that is normalised by the wall shear velocity. To systematically represent flow velocity, the Prandtl van Karman type velocity distribution's logarithmic-wall law was utilised by Keulegan [10] in his investigation on rectangular open channel flow. To improve Keulegan's study, Coles [6] proposed the log-wake law with a wake correction to more precisely represent velocity distribution at the outer flow region where the ratio of flow vertical location to full flow depth $(\mathrm{z} / \mathrm{h})$ is bigger than 0.2. Coles' method has been proven to give better accuracy compared to the log-wall law, as concluded by Song and Graf [29] and Dey and Raikar [7]; as well as in the modified log-wake law study by Yang [32].

The turbulence structure, including the time-averaged turbulence intensity and Reynolds stress, is produced from the Reynolds decomposed elements of instantaneous flow velocity. The same as the velocity log profile, the wall shear velocity is often used to normalise the turbulence intensity and Reynolds stress. This normalisation allows the turbulence representation in a scale benchmarked by the wall value so to permit comparison between different data sets collected under different hydraulic and wall boundary conditions. There are several ways to determine the shear velocity [27], in which two common approaches are: (1) the extrapolation method from the measured Reynolds stress profile, and (2) the energy gradient method. These methods have been shown to give reasonable estimation of the wall shear velocity $[7,28]$ providing that the wall boundary is relatively uniform through longitudinal space, i.e. particularly suitable for smooth bed flows. In comparison, the Reynolds stress profile extrapolation method has been found to be more prone to error as it is more dependent to the near bed/inner flow region measurements. For the measuring technique utilised in this study, Acoustic Doppler Velocimeter (ADV), the quality of the measured signal-to-noise ratio (SNR) can be sensitive to the reflective signals from wall boundary [35]. On the other hand, the energy gradient method involves the use of basic flow parameters, such as the hydraulic radius and bed slope; hence it is more error-resistant in calculating shear velocity [24, 25].

Accelerating [5] and decelerating flows [9, 22, 32] were studied to understand the characteristics of non-uniform flow. The strategy adopted for the analysis of non-uniform time-averaged velocity and turbulence characteristics was usually based on comparison to the uniform flow profiles $[9,33]$. Nezu et al. [18] first suggested the representation of nonuniform flow characteristics using the indication of streamwise pressure gradient. According to their study, due to the existence of the pressure gradient in the non-uniform flows, the velocity distribution should be characterised by non-constant wake parameter $\Pi$ and log-law integration constant $\mathrm{B}_{\mathrm{r}}$. Kironoto and Graf [14] and Song and Chiew [28] further detailed the change of $B_{r}$ and $\Pi$ values using a pressure gradient parameter $\beta$, which is defined by

$$
\beta=\frac{h}{\tau_{o}} \frac{\partial P}{\partial x}
$$

where $\mathrm{h}$ is the water flow depth, $\tau_{\mathrm{o}}$ is the bed shear stress, and $\partial P / \partial x$ is the flow pressure gradient. The work on $\beta$-effects on flow non-uniformity has been further expanded in the study by Onitsuka et al. [22]. All these studies showed that the non-uniform flow turbulence intensity and Reynolds stress can be well-represented by expression of $\beta$.

In this study, we attempt to compare the non-uniform flow turbulence patterns in subcritical flow regime over smooth bed. It aims to investigate the non-uniformity impact to the time-averaged spatial flow velocity, turbulence intensity and Reynolds stress profiles 
and to find their respective relationship to flow pressure gradient. To this end, these nonuniform flow profiles are also compared with previous literature findings to investigate their flow properties and to identify the flow behaviour under different types of nonuniform flows (i.e. accelerating and decelerating flows). Compared to previous works, this study identifies clearer dominant characteristics between the tested accelerating and decelerating flows which can add to the existing knowledge and tests of the non-uniform flow.

\section{Experimental description}

Figure 1 shows the general layout of the hydraulic flume used in this study. The experimental instrumentation and flow conditions are described in details here.

\subsection{Experimental instrumentations}

The flume presented in Fig. 1 has dimensions of $12 \mathrm{~m} \times 0.50 \mathrm{~m} \times 0.45 \mathrm{~m}$, and it is a recently refurbished flume located at the Hydraulic Laboratory, University of Bradford [26]. The flume is operated by a circulating system, where the outlet discharge is directed into a filtering tank then to a water pump system to be re-circulated back into the flume. The flume consists of glass walls and a smooth stainless-steel base. A flat gate is located at the channel end to control the flow depth in the flume. Two parallel tracks are utilised on

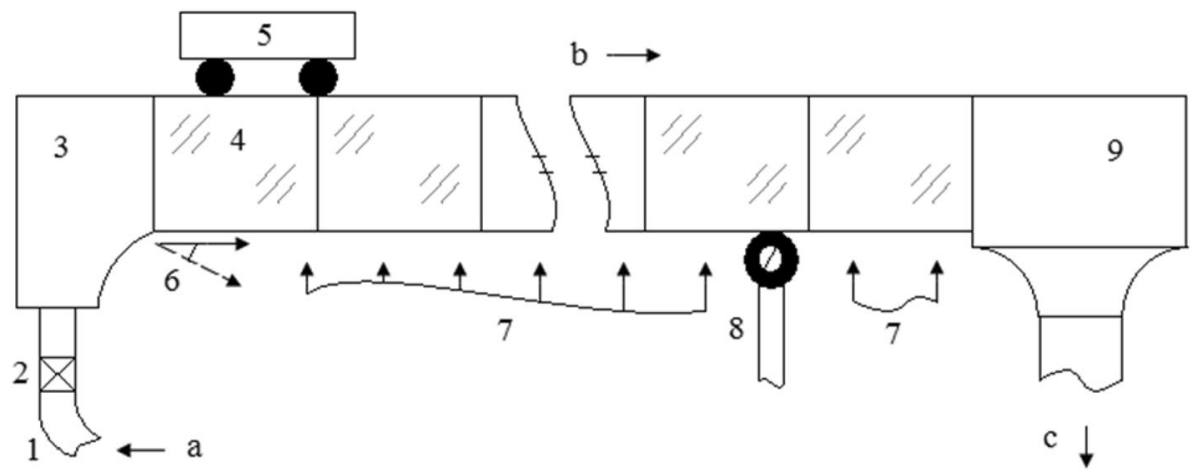

Parts of the Flume:

1. Inlet Water Pipe

2. Discharge Controlling Valve

3. Inlet Tank

4. Glass Wall

5. Trolley to Attach ADV

6. Angle of Flume Tilting

7. Flume Support from Truss Structure

8. Flume Tilting Mechanism

9. Outlet/Settling Tank
Flow Directions:

a. Inlet Flow from Water Pump

b. Flow in Flume

c. Outlet Flow

Fig. 1 Sketch layout of the experimental flume with dimensions of $12.0 \mathrm{~m} \times 0.5 \mathrm{~m} \times 0.45 \mathrm{~m}$ (re-adapted using similar figure to Fig. 1 at [25]) 
top of the flume for attaching measuring trolley used for holding and securing the ADV equipment.

The employed ADV has down-looking probes-product of the Nortek Ltd. (Vectrino $\mathrm{ADV}$ ). It has a limitation of $5 \mathrm{~cm}$ measuring distance downward from the probe location, which restricts the data collection at $5 \mathrm{~cm}$ vertical distance near to the water flow free surface. The ADV is equipped with the four-probe-receiver, which can significantly reduce the noise signal of the measurements as compared with the three-probe-receiver ADV [3].

\subsection{Experimental conditions}

Table 1 presents a summary of all conditions in the hydraulically smooth uniform and nonuniform flow experiments conducted in this study. Besides the common parameters, the table also includes a roughness Reynolds number, $\mathrm{Re}_{\mathrm{k}}$, to indicate and confirm the smooth bed property used in this study [34]. The velocity measurements for the non-uniform flows (Test 2, 3, 4 and 5) are taken at four streamwise locations (at 3, 5, 6 and $7 \mathrm{~m}$ from the flume inlet). For the uniform flow test (Test 1), the measurements are conducted at five different streamwise locations from upstream to downstream to ensure its uniformity characteristic. At each streamwise location, the velocity measurements are recorded at 15-20 vertical positions. Each sampling point can have a minimum sampling volume size of $1 \mathrm{~mm}^{3}$; however, for the measurement point that has low SNR ratio (lower than $18 \mathrm{~dB}$ ), the sampling volume is increased. In all tests, all the point velocity measurements are conducted at a sampling frequency of $100 \mathrm{~Hz}$ for $5 \mathrm{~min}$.

\section{Uniform flow results and analysis}

The normalised velocity profile for smooth bed uniform flow can be represented by the logwake law originated from Prandtl-van Karman log velocity distribution as follows [19]

$$
u^{+}=\frac{1}{\kappa} \ln \left(z^{+}\right)+B_{r}+\frac{2 \Pi}{\kappa} \sin ^{2}\left(\frac{\pi \cdot z}{2 \cdot \delta}\right)
$$

where $u^{+}=u(z) / u_{*}, z^{+}=\left(u_{*} \cdot z\right) / v, \mathrm{z}$ is the vertical distance, $u(z)$ is flow velocity at distance $\mathrm{z}, u_{*}$ is the shear velocity, $\delta$ is the water depth where the maximum velocity occurs (in our case $\delta=\mathrm{h}$ ), and $v$ is the kinematic viscosity. In Eq. (2), the first two items

Table 1 Summary of experimental conditions in uniform and non-uniform flows

\begin{tabular}{llllllll}
\hline $\begin{array}{l}\text { Test } \\
\text { no. }\end{array}$ & $\begin{array}{l}\text { Channel slope } \\
\left(\times 10^{-3}\right)\end{array}$ & $\begin{array}{l}\text { Discharge } \\
\left(\mathrm{m}^{3} / \mathrm{s}\right)\end{array}$ & $\mathrm{Fr}^{\mathrm{a}}(-)$ & $\begin{array}{l}\mathrm{Re}_{\mathrm{k}}^{\mathrm{b}} \\
(-)\end{array}$ & $\begin{array}{l}\text { Flow } \\
\text { characteristic }\end{array}$ & $\begin{array}{l}\text { Bed } \\
\text { condition }\end{array}$ & $\begin{array}{l}\text { Measuring } \\
\text { locations } \\
\text { presented }\end{array}$ \\
\hline 1 & 1.25 & 0.0315 & 0.55 & 28 & Uniform & Smooth & Multiple \\
2 & 0 & 0.0270 & $0.42-0.66$ & $21-22$ & Non-uniform & Smooth & Multiple \\
3 & 0 & 0.0315 & $0.41-0.57$ & $23-24$ & Non-uniform & Smooth & Multiple \\
4 & 0 & 0.0360 & $0.44-0.77$ & $22-29$ & Non-uniform & Smooth & Multiple \\
5 & 2.50 & 0.0315 & $0.63-0.87$ & $20-32$ & Non-uniform & Smooth & Multiple \\
\hline
\end{tabular}

${ }^{\mathrm{a}} \mathrm{Fr}$ is the Froude number where $\mathrm{Fr}=\mathrm{u} / \sqrt{ }(\mathrm{g} \delta)$

${ }^{\mathrm{b}} \mathrm{Re}_{\mathrm{k}}$ is the roughness Reynolds number where $\mathrm{Re}_{\mathrm{k}}=\mathrm{u}_{*} \mathrm{k}_{\mathrm{S}} / v$ and $\mathrm{k}_{\mathrm{s}}$ is the roughness height of the bed 
on the right-hand side represent the log-wall law function and the inclusion of the last expression on the right-hand side provides the wake function to the log law.

For the von Karman constant $\kappa$ in Eq. (2), relatively consistent values have been found in different literature studies. A range of $\kappa=0.40-0.42$ was proposed for the flows over smooth bed investigated by Coles [6] and Cardoso et al. [4]; while, similar value $(\kappa=0.40)$ was also suggested for the rough bed flow by Song et al. [30]. More recently, Auel et al. [2] summarised from various smooth and rough bed flow studies that $\kappa=0.385-0.435$, universally. For the log-law integration constant $\mathrm{B}_{\mathrm{r}}$ of smooth bed uniform flows, it was proposed as $\mathrm{B}_{\mathrm{r}}=4.9$ in Mellor and Gibson [15], and Anwar and Atkins [1]; and $\mathrm{B}_{\mathrm{r}}=5.1$ in Coles [6], and Cardoso et al. [4]. In comparison to different rough bed flow studies (i.e. $\mathrm{B}_{\mathrm{r}}=8.47 \pm 0.90$ in [13]; $\mathrm{B}_{\mathrm{r}}=8.42 \pm 0.22$ in [30]; and $\mathrm{B}_{\mathrm{r}}=7.80 \pm 0.37$ in [7]), the smooth bed flow was found to have lower $\mathrm{B}_{\mathrm{r}}$ value.

For the wake parameter $\Pi$, different estimations were made in various literature studies for the smooth bed uniform flow. In those studies, some have suggested higher values, namely Nezu and Rodi $[20]-\Pi=0.20$; while others proposed lower values, namely Kirkgoz [11] $-\Pi=0.10$, Steffer et al. [31] $-\Pi=0.08-0.15$, and Cardoso et al. [4]$\Pi=0.079 \pm 0.093$. When compared to rough bed flow studies, i.e. $\Pi=0.09$ by Kironoto and Graf [13], $\Pi=0.08$ by Song et al. [30], and $\Pi=0.110 \pm 0.026$ by Dey and Raikar [7], $\Pi$ does not show separate distinct values for flow over different bed roughness.

\subsection{Discussion}

In Fig. 2, the $\mathrm{u}^{+}$distribution profiles for Test 1 are used to empirically verify $\kappa$, and to calculate $B_{r}$ and $\Pi$ constants appeared in Eq. (2). The shear velocity in this test has been obtained using the bed shear stress calculated from the uniform pressure gradient approach as follows

$$
u_{*}=\sqrt{g R S_{o}}
$$

where $\mathrm{g}$ is the gravitational acceleration, $\mathrm{R}$ is the hydraulic radius, and $\mathrm{S}_{\mathrm{o}}$ is the bed slope. The measurements at five different locations across up- to downstream for Test 1 show the unchanged coefficient values of $\kappa, B_{r}$ and $\Pi$ to be $0.43,4.7$, and 0.0754 , respectively. These parameters are found to give consistent values with most of the other smooth bed uniform flow studies discussed in this section; however, 0.43 is found to be at the higher end of $\kappa$ range proposed by Auel et al. [2].

To carry out the turbulence structure analysis, the 3D turbulence intensities for Test 1 are investigated. The well-known theory of Nezu [16] has been employed to express the 3D turbulence intensities in exponential form as follows

$$
\begin{aligned}
& \frac{\sqrt{\overline{u^{2}}}}{u_{*}}=D_{1} e^{-\lambda_{1}(z / \delta)} \\
& \frac{\sqrt{\overline{v^{2}}}}{u_{*}}=D_{2} e^{-\lambda_{2}(z / \delta)} \\
& \frac{\sqrt{\overline{w^{2}}}}{u_{*}}=D_{3} e^{-\lambda_{3}(z / \delta)}
\end{aligned}
$$

where $\mathrm{u}^{\prime}, \mathrm{v}^{\prime}$ and $\mathrm{w}^{\prime}$ represent the velocity fluctuations in 3D streamwise, lateral and vertical directions, respectively, and $\mathrm{D}_{1}, \mathrm{D}_{2}, \mathrm{D}_{3}, \lambda_{1}, \lambda_{2}$ and $\lambda_{3}$ are all empirical constants for the $3 \mathrm{D}$ 


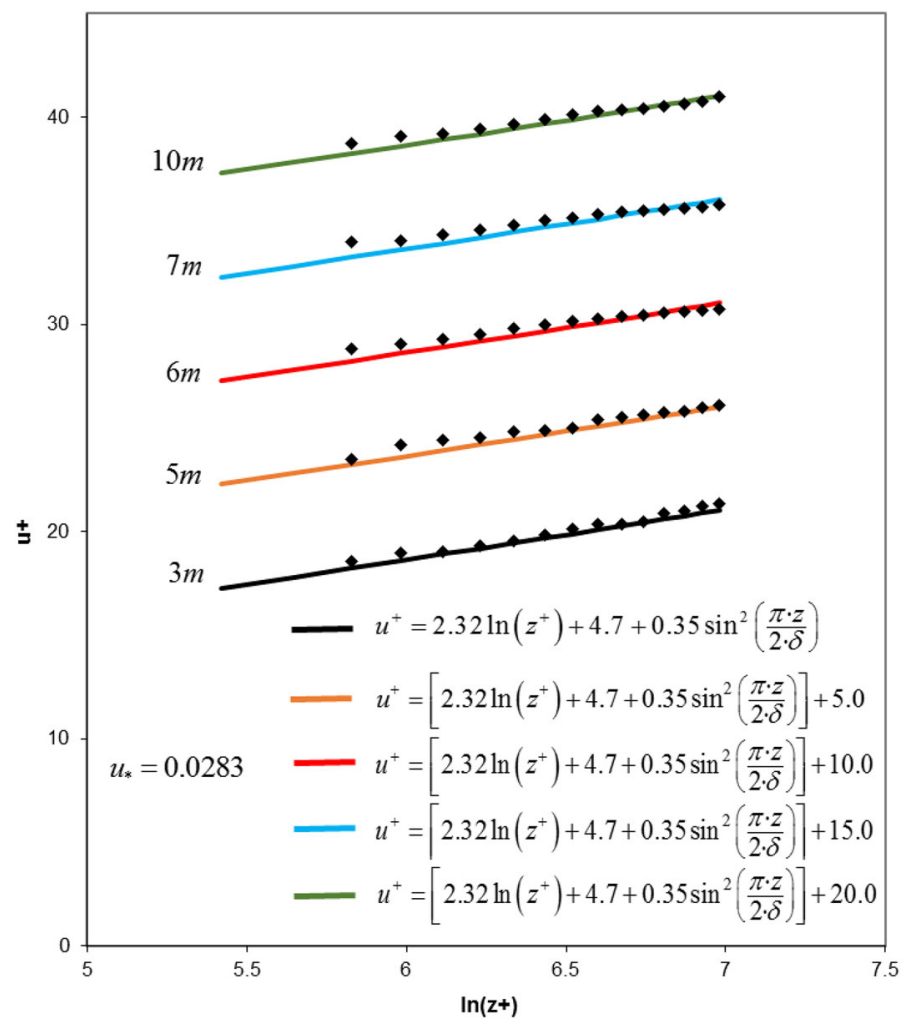

Fig. 2 Measured normalised flow velocity profile at five different streamwise locations (Test 1-uniform flow). Symbols: measurements; line: log-wake law calculation

turbulence intensities. It can be observed from Fig. 3 that the measured turbulence intensity profiles (symbols) at all five measured locations correspond reasonably with Eqs. (4)-(6) (lines) in which their regression coefficients $\mathrm{R}^{2}$ falls between 0.75 and 0.83 . For the lateral turbulence intensity profile, Papanicolaou and Hilldale [23] reported that $\mathrm{D}_{2}$ and $\lambda_{2}$ should be slightly larger than $\mathrm{D}_{3}$ and $\lambda_{3}$, which is in agreement with our finding. All turbulence intensity empirical constants from this study have been compared to literature findings in Table 2 . The measured streamwise and vertical profiles in this study are slightly higher than others' data presented in Table 2, which is resulted from the higher $\mathrm{u}_{*}=2.83 \mathrm{~cm} / \mathrm{s}$ employed in this study. This finding shows that even in hydraulically smooth flow condition the wall shear stress may affect turbulence intensity profiles within a high flow depth in streamwise and vertical directions provided that $\mathrm{R}$ and $\mathrm{h}$ are not large. Auel et al. [2] has consistently suggested this same conclusion in their supercritical flow tests with relatively small $\mathrm{R}$ and $\mathrm{h}$ settings. 


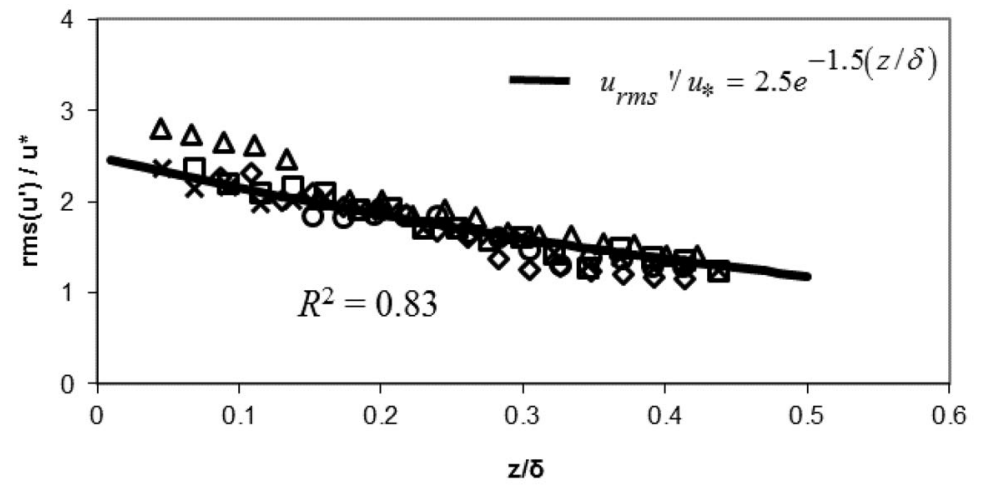

$\mathbf{0} 3 \mathrm{~m}$ Location
$\mathbf{\Delta} 5 \mathrm{~m}$ Location
-6m Location
$\mathbf{0} 7 \mathrm{~m}$ Location
$\mathbf{x} 10 \mathrm{~m}$ Location

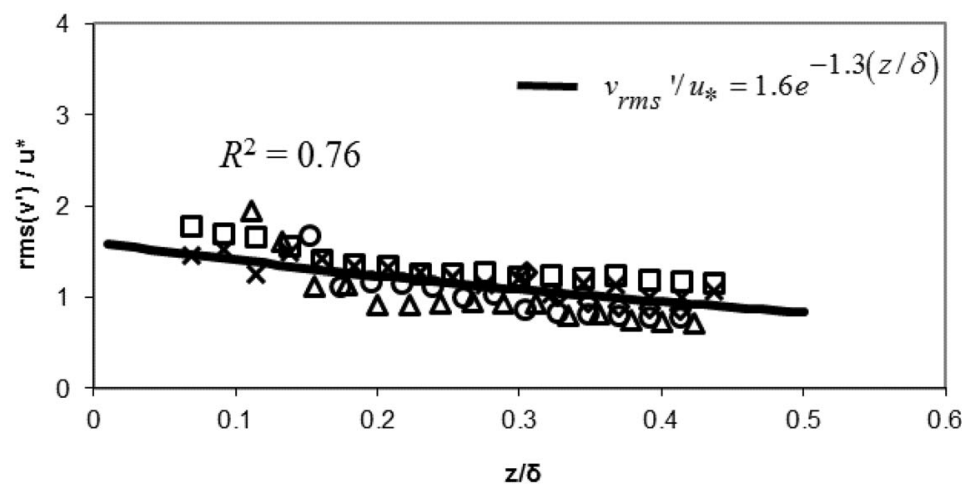

口 3 m Location
\5m Location
- 6 m Location
- 7 m Location
×10m Location

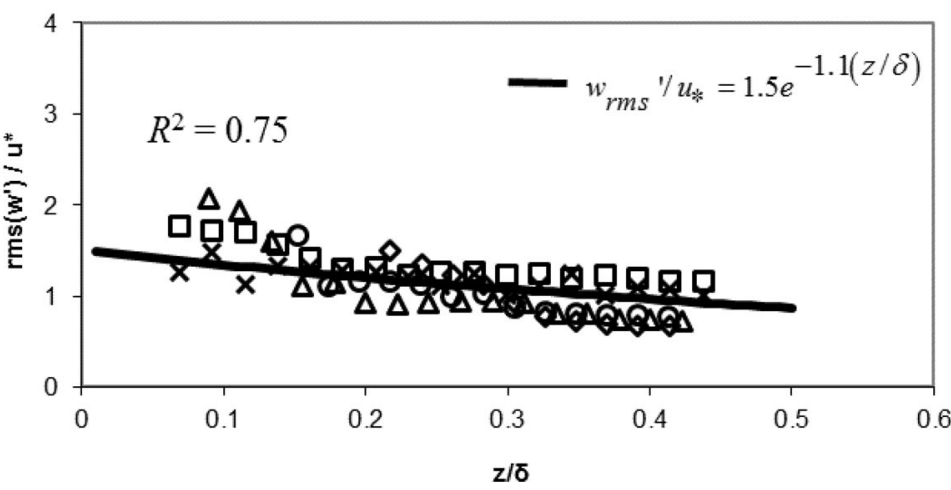

- 3 m Location
வ 5 m Location
- 6 m Location
- 7 m Location
$\times 10$ m Location

Fig. 3 Measured normalised flow turbulence intensity profiles at five different streamwise locations (Test 1-uniform flow). Symbols: measurements; line: exponential law fits from Nezu [16]

\section{Non-uniform flow results and analysis}

The non-uniform flow, which is characterised by the existence of a streamwise pressure gradient, has also been investigated. Four separate flow tests (Tests 2-5) have been carried out during this study. Tests 2-4 have accelerating flow characteristics; while Test 5 presents the decelerating flow characteristics. Table 3 describes the recorded depth-averaged velocity along the streamwise flow direction; while Fig. 4 shows the measured flow depths 
Table 2 Empirical constants from present study and literature for turbulence intensity exponential law

\begin{tabular}{llllllll}
\hline Sources & $\mathrm{D}_{1}$ & $\mathrm{D}_{2}$ & $\mathrm{D}_{3}$ & $\lambda_{1}$ & $\lambda_{2}$ & $\lambda_{3}$ & Bed condition(s) \\
\hline Present Study & 2.50 & 1.60 & 1.50 & 1.50 & 1.30 & 1.10 & Smooth \\
Cardoso et al. [4] & 2.28 & - & - & 1.08 & - & - & Smooth \\
Nezu and Azuma [17] & 2.30 & - & 1.27 & 1.00 & - & 1.00 & Smooth and rough \\
Noguchi and Nezu [21] & 2.30 & - & 1.20 & 1.25 & - & 1.00 & Smooth and rough \\
\hline
\end{tabular}

${ }^{a} D_{1}, D_{3}, \lambda_{1}$, and $\lambda_{3}$ values are deduced from the turbulence intensity profiles of smooth and rough bed flows that closely collapse together

Table 3 Depth-averaged u-velocity data of different locations for Tests 2-5

\begin{tabular}{llllll}
\hline Test no. & Flow characteristic & \multicolumn{4}{l}{$\mathrm{u}$-velocity $(\mathrm{m} / \mathrm{s})$, flow depth $(\mathrm{cm})$} \\
\cline { 3 - 6 } & & $3 \mathrm{~m}$ & $5 \mathrm{~m}$ & $6 \mathrm{~m}$ & $7 \mathrm{~m}$ \\
\hline 1 & Uniform & $0.566,11.0$ & $0.566,11.1$ & $0.566,11.0$ & $0.566,11.0$ \\
2 & Accelerating & $0.482,11.2$ & $0.502,10.8$ & $0.505,10.7$ & $0.510,10.6$ \\
3 & Accelerating & $0.509,12.3$ & $0.517,12.1$ & $0.519,12.0$ & $0.528,11.9$ \\
4 & Accelerating & $0.551,13.0$ & $0.555,12.8$ & $0.564,12.6$ & $0.599,12.2$ \\
5 & Decelerating & $0.788,8.0$ & $0.757,8.3$ & $0.695,8.8$ & $0.686,9.2$ \\
\hline
\end{tabular}

${ }^{\mathrm{a}}$ It is found by depth averaging of the time-averaged u-velocity

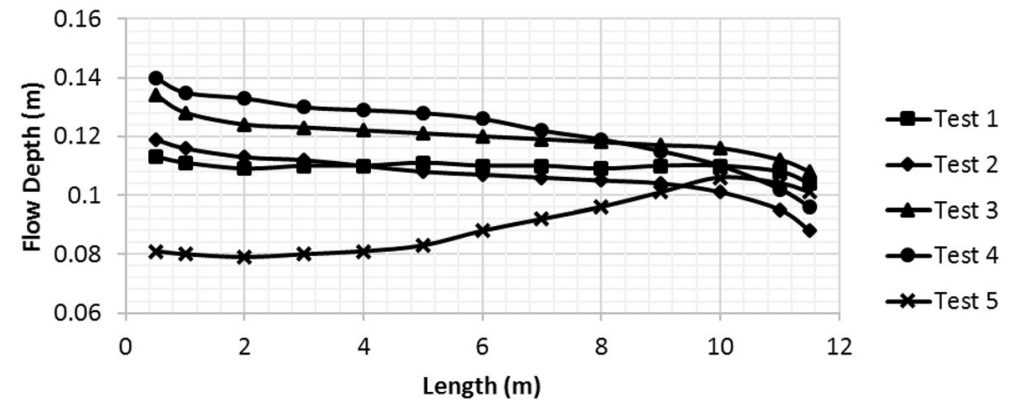

Fig. 4 Measured flow depth along channel location for Tests 1-5

across the channel for each test. All tested flows in this study have aspect ratio between 3.57 and 6.33 (recorded from $0.5 \mathrm{~m}$ upstream to $11.5 \mathrm{~m}$ downstream of the channel). For the non-uniform flow, its pressure gradient is represented by

$$
\frac{\partial P}{\partial x}=g \rho\left(-S_{o}+\frac{d h}{d x}\right)
$$

where $\rho$ is the density of water, and $d h / d x$ is the flow streamwise water level gradient.

The pressure gradient parameter $\beta$ [determined by Eq. (1) using pressure gradient in Eq. (7)] was utilised to calculate the change of velocity and turbulence structure for nonuniform flow in Song et al. [30], Kironoto and Graf [14] and Song and Chiew [28]. For 
uniform flow, $\beta$ has a constant value of -1 ; whereas for the non-uniform flow, $\beta$ is nonconstant (as suggested by $[2,14,28]$ ). As both $B_{r}$ and $\Pi$ of the non-uniform flow are in the function of $\beta$, the non-uniform flow's log-wake law should therefore be expressed as

$$
u^{+}=\frac{1}{\kappa}\left[\ln \left(z^{+}\right)\right]+B_{r}(\beta)+\frac{2 \Pi(\beta)}{\kappa} \sin ^{2}\left(\frac{\pi \cdot z}{2 \cdot \delta}\right)
$$

\subsection{Discussion}

Figures 5, 6, 7 and 8 show the comparisons between the log-wake law and experimental data for Tests 2-5. The measurements correspond to the log-wake law. The shear velocity for the non-uniform flow can be calculated using the energy gradient method as follows

$$
u_{*}=\sqrt{g R\left[S_{o}-\frac{d h}{d x}\left(1-F r^{2}\right)\right]}
$$

where Fr is the Froude number. This method was proven in Pu et al. [25] and Pu [24] to accurately compute the non-uniform flow's shear velocity. As it is derived from the basic flow principle, its parameters can be measured with much less uncertainty. In Table 4, the shear velocity calculated by the energy gradient method have been compared to those found by the Reynolds stress profile method. The Reynolds stress profile method calculates $u_{*}$ by relating the bed shear stress expression of $-\overline{u^{\prime} w^{\prime}}$ to an expression of $u_{*}^{2}(1-z / \delta)$. Both methods have the calculated $u_{*}$ in good agreement with each other. The values of all the empirical $\kappa, B_{r}$ and $\Pi$ constants for Test 2-5 are also presented in Table 4 . These values have been used to produce Fig. 9, where the accelerating flow falls in the region of $\beta<-1$; while the decelerating flow falls in the region of $\beta>-1$.

From the results at Figs. 5, 6, 7 and 8, an analysis has been conducted to find out the influence of non-uniformity towards log-wake law. To this end, Fig. 9 is produced to investigate the impact of non-uniformity on $\kappa, B_{\mathrm{r}}$ and $\Pi$ constants. The measurements in Fig. 9a show that the von Karman constant $\kappa$ remains unchanged across the investigated $\beta$ range at about 0.43 with regression coefficient $R^{2}$ of 0.92 compared to measured data, and this consistency remains for both accelerating and decelerating flow tests. The constant $\kappa=0.43$ is also within the $\kappa$ range proposed in Auel et al. [2]. In Fig. 9b, this study's $B_{r}$ remains constant at around $B_{r}=8.1$ with regression coefficient $R^{2}$ of 0.84 compared to measured data. When compared to rough bed non-uniform flow $\mathrm{B}_{\mathrm{r}}$, such as 8.5 proposed by Kironoto and Graf [14] and 8.21-8.61 proposed by Song and Chiew [28], $\mathrm{B}_{\mathrm{r}}$ proposed in this study agrees well with them. In their rough bed flow's log-wake law, their utilised parameter $\mathrm{z}^{+}$was affected by bed roughness. This comparison shows the universality of non-uniform flow $B_{r}$ in different bed roughness. Figure $9 c$ shows that the wake parameter $\Pi$ is varying with $\beta$ in non-uniform flows. The experimental data here is compared with non-uniform flow formulae proposed for the smooth bed flow by Nezu et al. [18] and for the rough bed flow by Kironoto and Graf [14], in which the data shows reasonably good agreement with both formulae. This comparison further suggests that the $\beta$-expression of $\Pi$ should be universal for both hydraulically rough and smooth non-uniform flows. From these $\kappa, B_{r}$ and $\Pi$ findings, it can be concluded that the log-wake law can sufficiently represent the non-uniform flow without needing any modification. The detailed analysis also reveals that all $\kappa, B_{\mathrm{r}}$ and $\Pi$ follow universal rules for different bed roughness conditions. 

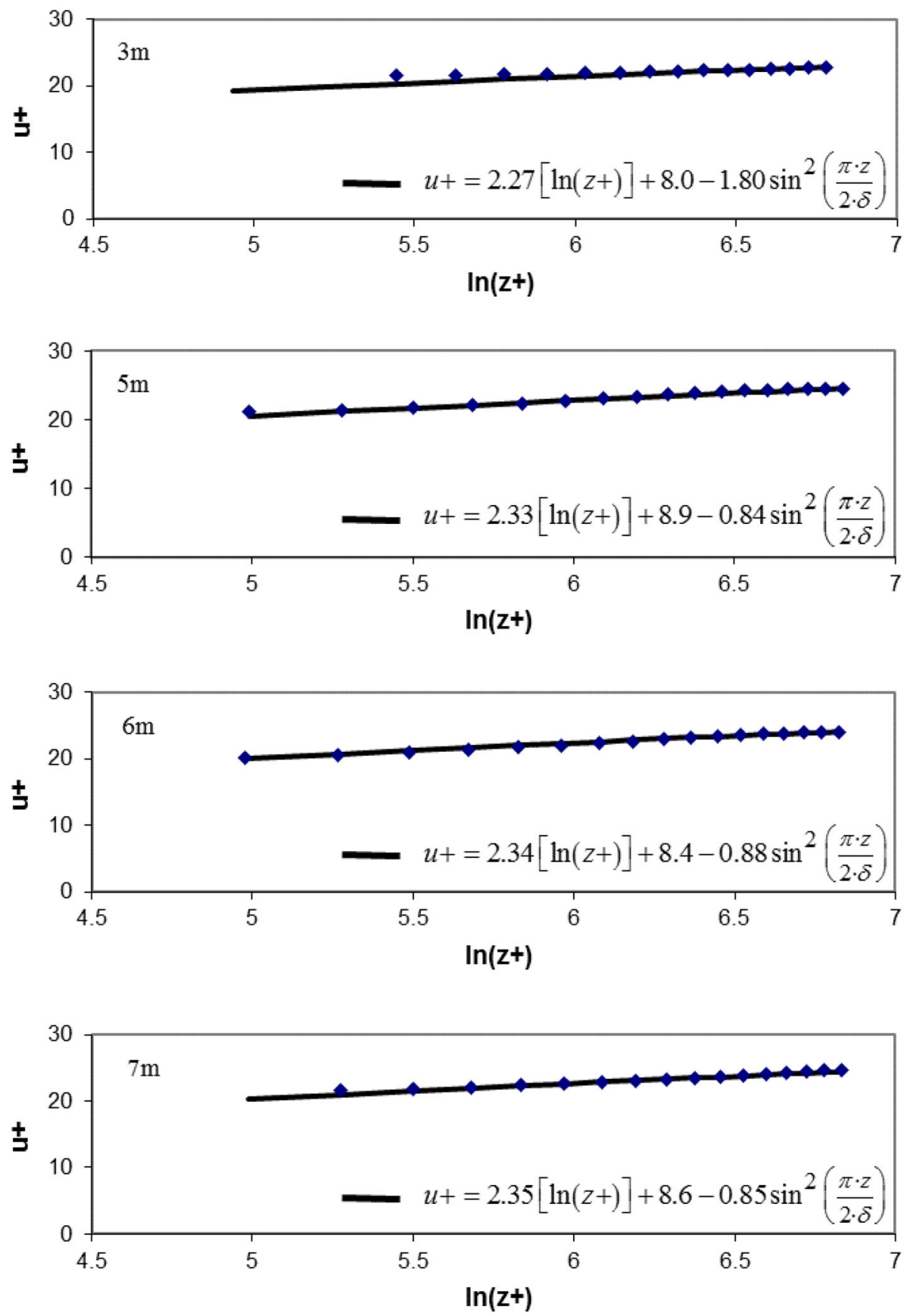

Fig. 5 Measured normalised velocity profiles of 3-7 m streamwise locations (Test 2-accelerating flow). Symbols: measurements; line: log-wake law calculation 

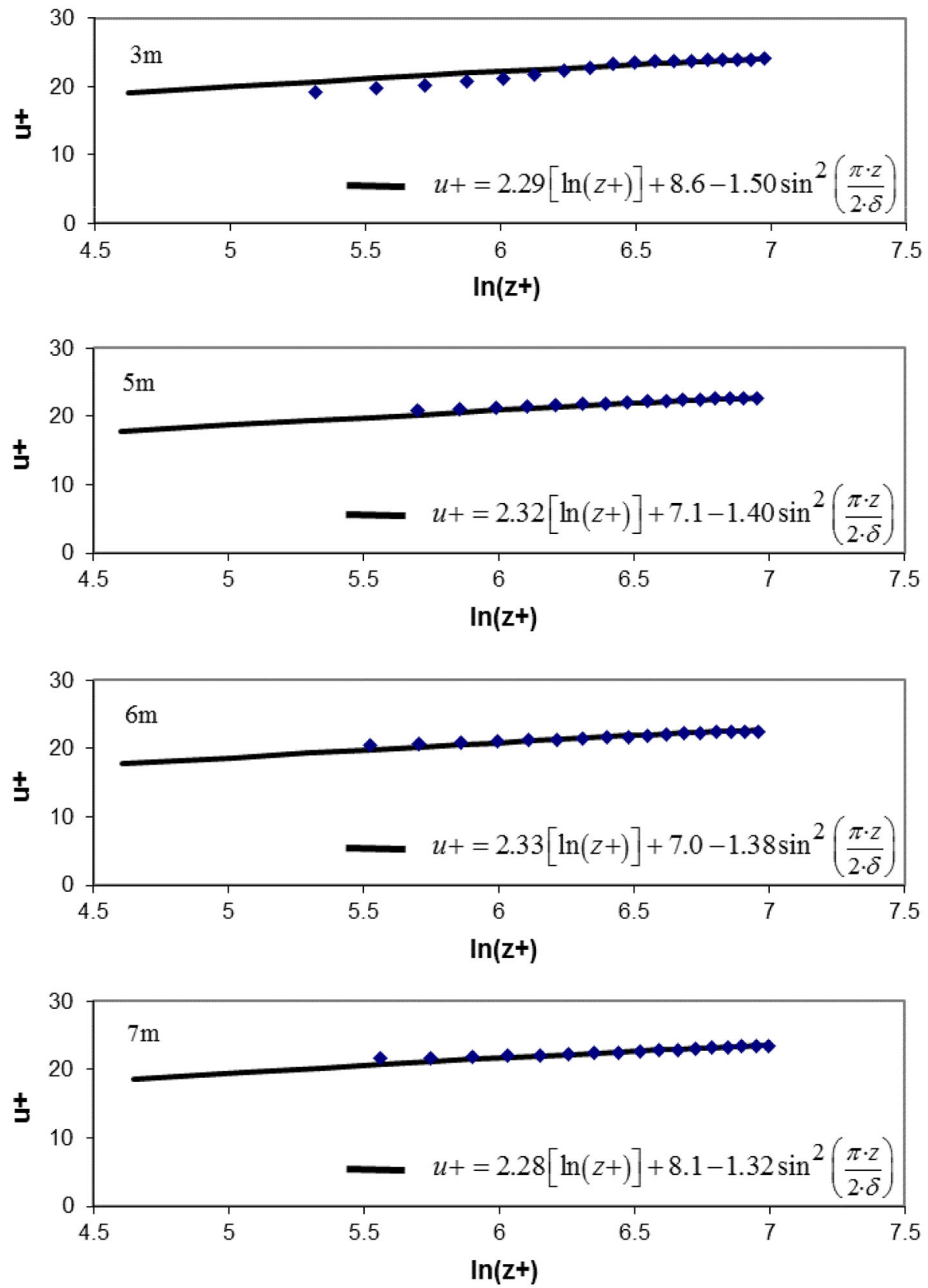

Fig. 6 Measured normalised velocity profiles of 3-7 m streamwise locations (Test 3-accelerating flow). Symbols: measurements; line: log-wake law calculation

A relationship suggested by Nezu et al. [18] and Kironoto and Graf [14] has been employed in this study to represent the 3D non-uniform flow turbulence intensities as follows 

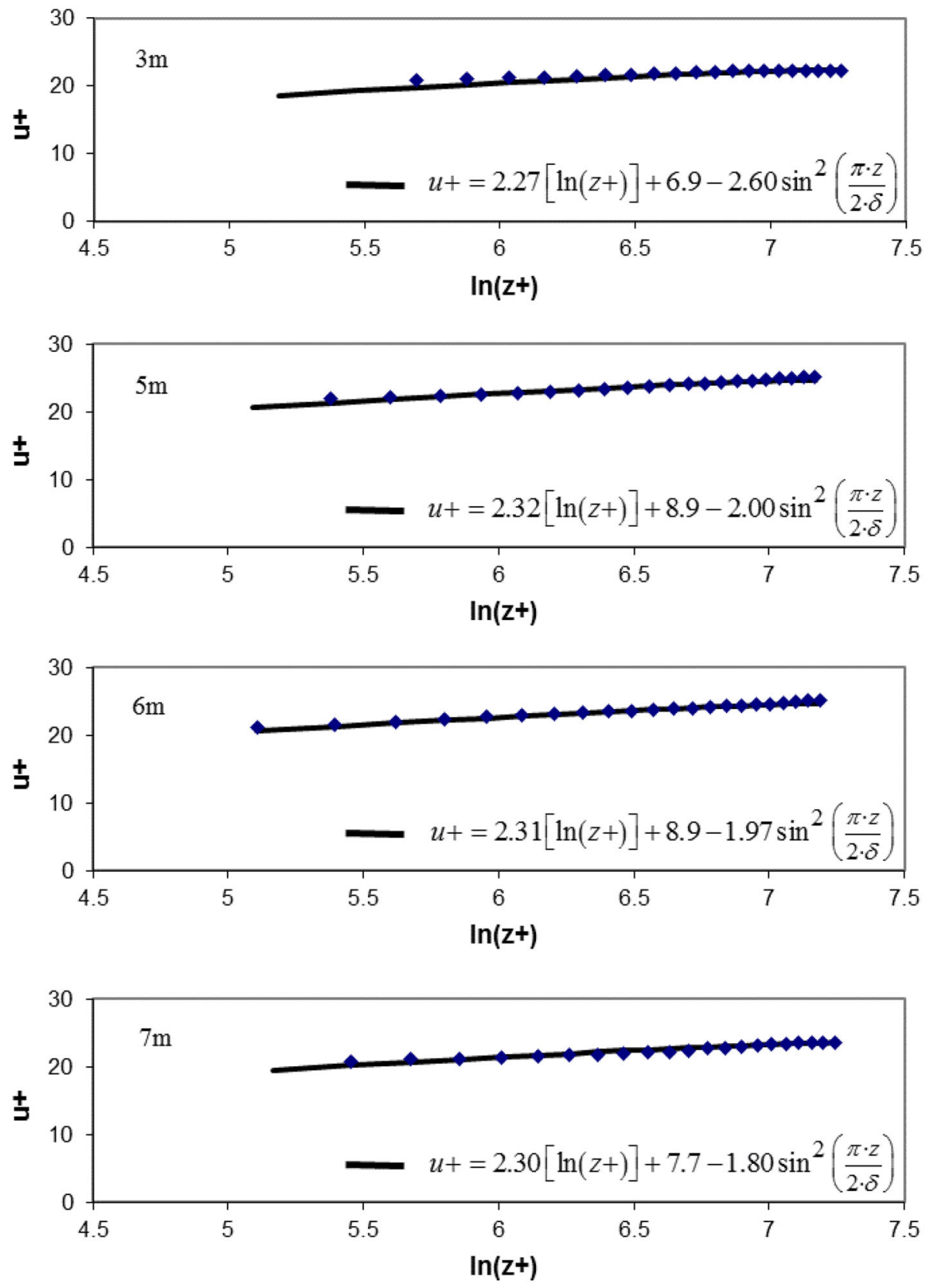

Fig. 7 Measured normalised velocity profiles of 3-7 m streamwise locations (Test 4-accelerating flow). Symbols: measurements; line: log-wake law calculation 

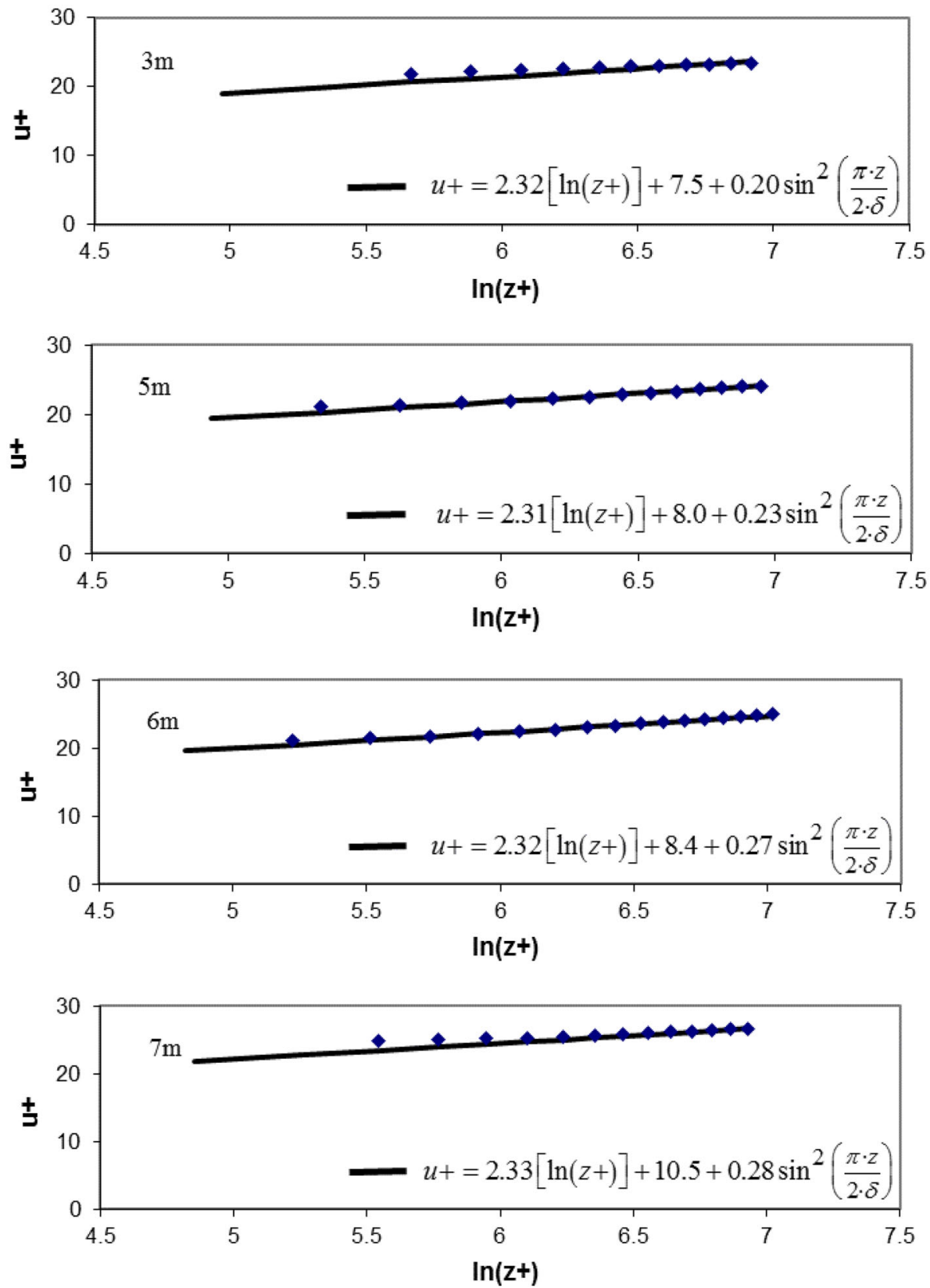

Fig. 8 Measured normalised velocity profiles of 3-7 m streamwise locations (Test 5-decelerating flow). Symbols: measurements; line: log-wake law calculation 
Table 4 Summary of data and parameters of the non-uniform flow tests (Tests 2-5)

\begin{tabular}{lllllllll}
\hline $\begin{array}{l}\text { Test } \\
\text { no. }\end{array}$ & $\begin{array}{l}\text { Streamwise location } \\
(\mathrm{m})\end{array}$ & $\begin{array}{l}\partial P / \partial x(\mathrm{~N} / \\
\left.\mathrm{m}^{3}\right)\end{array}$ & $\beta(-)$ & $\kappa(-)$ & $\begin{array}{l}\mathrm{B}_{\mathrm{r}}(- \\
\text { II }(-)\end{array}$ & $\begin{array}{l}\mathrm{u}_{* 1}^{\mathrm{a}}(\mathrm{cm} / \\
\mathrm{s})\end{array}$ & $\begin{array}{l}\mathrm{u}_{*}^{\mathrm{b}}(\mathrm{cm} / \\
\mathrm{s})\end{array}$ \\
\hline 2 & 3 & -13.734 & -3.098 & 0.441 & 8 & -0.397 & 2.17 & - \\
& 5 & -13.93 & -2.729 & 0.429 & 8.9 & -0.180 & 2.10 & 2.09 \\
& 6 & -14.028 & -2.590 & 0.427 & 8.4 & -0.188 & 2.13 & 2.11 \\
& 7 & -14.126 & -2.153 & 0.425 & 8.6 & -0.181 & 2.12 & - \\
3 & 3 & -15.5 & -4.941 & 0.437 & 8.6 & -0.328 & 2.30 & - \\
& 5 & -15.598 & -4.798 & 0.431 & 7.1 & -0.302 & 2.33 & 2.36 \\
& 6 & -15.696 & -5.164 & 0.429 & 7 & -0.296 & 2.35 & - \\
& 7 & -15.794 & -4.343 & 0.439 & 8.1 & -0.290 & 2.32 & 2.31 \\
4 & 3 & -16.088 & -6.809 & 0.44 & 6.9 & -0.572 & 2.23 & - \\
& 5 & -16.187 & -6.223 & 0.431 & 8.9 & -0.431 & 2.34 & 2.29 \\
& 6 & -16.285 & -5.886 & 0.433 & 8.9 & -0.427 & 2.75 & 2.78 \\
& 7 & -16.383 & -6.160 & 0.435 & 7.7 & -0.392 & 2.91 & - \\
5 & 3 & 37.278 & 0.443 & 0.431 & 7.5 & 0.043 & 2.06 & - \\
& 5 & 37.180 & 0.641 & 0.433 & 8 & 0.050 & 2.51 & - \\
& 6 & 37.082 & 0.728 & 0.431 & 8.4 & 0.058 & 3.10 & 3.06 \\
& 7 & 36.984 & 0.743 & 0.429 & 10.5 & 0.060 & 3.19 & 3.17 \\
\hline
\end{tabular}

${ }^{\mathrm{a}} \mathrm{u}_{* 1}=$ shear velocity calculated from energy gradient method of Eq. (9)

${ }^{\mathrm{b}} \mathrm{u}_{*_{2}}=$ shear velocity obtained from measured Reynolds stress profiles (by eliminating the most bottom fluctuating point, if exists)

$$
\begin{aligned}
& \frac{\sqrt{\overline{u^{\prime 2}}}}{u_{*}}=D_{1}(\beta) e^{-\lambda_{1}(\beta)(z / \delta)} \\
& \frac{\sqrt{\overline{v^{\prime 2}}}}{u_{*}}=D_{2}(\beta) e^{-\lambda_{2}(\beta)(z / \delta)} \\
& \frac{\sqrt{\overline{w^{\prime 2}}}}{u_{*}}=D_{3}(\beta) e^{-\lambda_{3}(\beta)(z / \delta)}
\end{aligned}
$$

where all the coefficients $D_{1}, D_{2}, D_{3}, \lambda_{1}, \lambda_{2}$, and $\lambda_{3}$ are in the function of $\beta$. Figures 10 and 11 are produced from the empirical coefficients in Eqs. (10)-(12), where the measured data are investigated across a range of $\beta$ from accelerating to decelerating flow regimes. The thin dash-lines in Figs. 10 and 11 represent the uniform flow region at $\beta=-1$. The proposed empirical quadratic relationships with $\beta$ are presented in Eq. (13) for $D_{1}, D_{2}$ and $\mathrm{D}_{3}$ with regression coefficient $\mathrm{R}^{2}$ of $0.88,0.85$ and 0.84 , respectively. In contrast, constant relationships can be seen for $\lambda_{1}, \lambda_{2}$, and $\lambda_{3}$ (with regression coefficient $R^{2}$ of $0.64,0.61$ and 0.61 , respectively) as in Eq. (14).

$$
\begin{aligned}
& D_{1}=0.006 \beta^{2}+0.172 \beta+2.598, \quad D_{2}=0.014 \beta^{2}+0.179 \beta+1.790, \quad \text { and }, \\
& D_{3}=0.007 \beta^{2}+0.147 \beta+1.770
\end{aligned}
$$



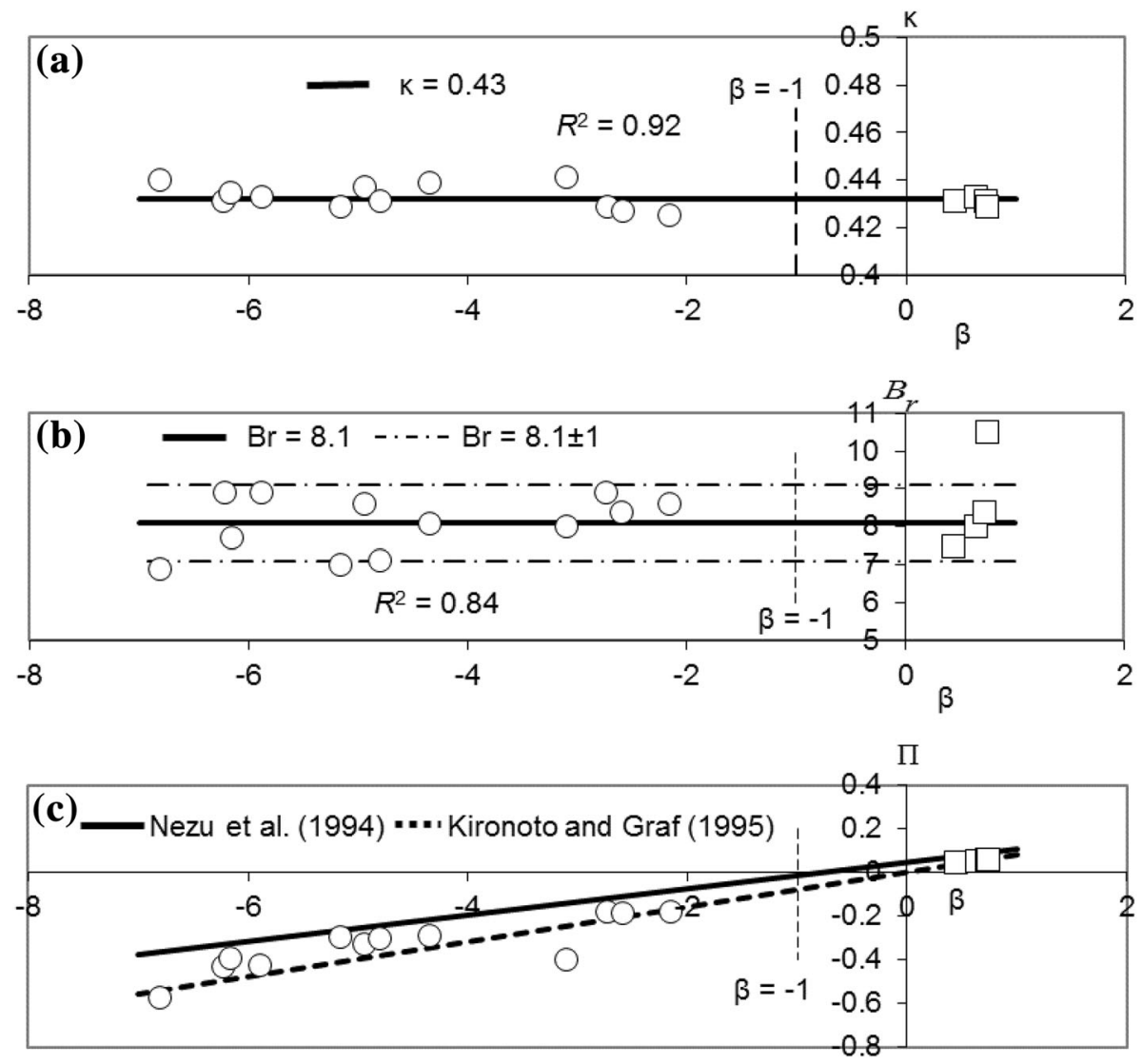

Fig. 9 Constants plot against $\beta-\mathbf{a} \kappa$ versus $\beta, \mathbf{b} \mathrm{B}_{\mathrm{r}}$ versus $\beta$ and $\mathbf{c} \Pi$ versus $\beta$. Circles: accelerating flow measurements; squares: decelerating flow measurements

$$
\lambda_{1}=1.14, \quad \lambda_{2}=0.82, \quad \text { and } \quad \lambda_{3}=0.75
$$

Two points can be observed from Eqs. (13)-(14): (a) all $\mathrm{D}_{1}, \mathrm{D}_{2}$ and $\mathrm{D}_{3}$ have consistent tendency to decrease from higher values at decelerating flow region to lower values at accelerating flow region in the investigated $\beta$ range; and (b) it is presented in Eq. (14) that $\lambda_{1}>\lambda_{2}>\lambda_{3}$. These findings suggest that the decelerating flow has higher 3D turbulence intensity profiles than the accelerating flow; and the turbulence intensity characteristics are more dominantly dictated by the streamwise flow. The fitted relationships of Eqs. (13)-(14) also represent the uniform flow data well, suggesting they are working across both the uniform and non-uniform flows.

Further investigations of the measured non-uniform flow Reynolds stresses are conducted using the equation below (proposed by [12])

$$
\frac{-\overline{u^{\prime} w^{\prime}}}{u_{*}^{2}}=D_{u w}(\beta)\left(1-\frac{z}{\delta}\right) e^{-\lambda_{u w}(\beta) \cdot(z / \delta)}
$$

where $D_{u w}$ and $\lambda_{\text {uw }}$ are the empirical constants for Reynolds stress profile. Figure 12 presents the measured Reynolds stress' constants in Eq. (15), which their quadratic 

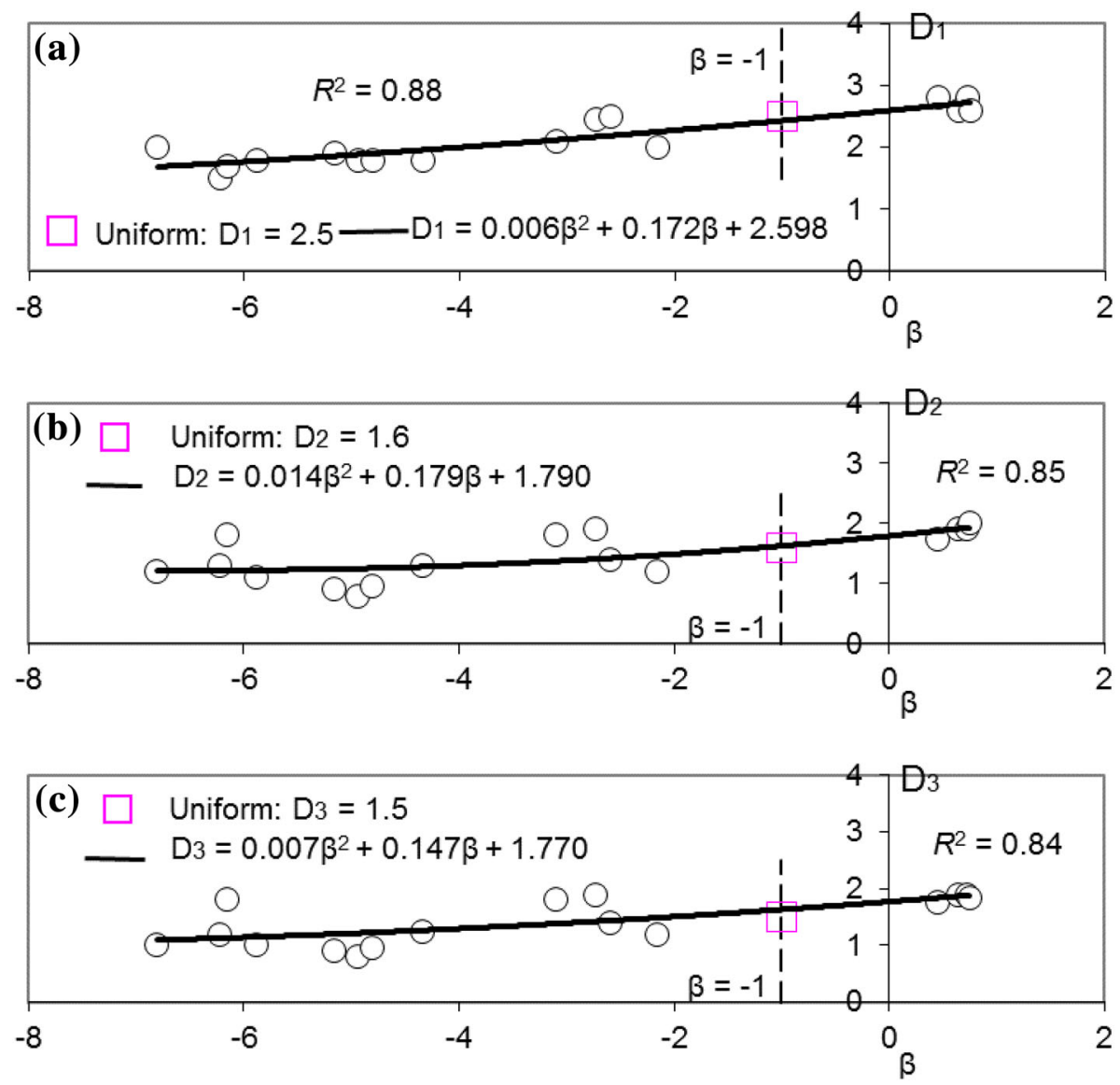

Fig. 10 Relationship of a $D_{1}$, b $D_{2}$, and $\mathbf{c} D_{3}$ with $\beta$ in Eqs. (10)-(12). Circles: non-uniform flow measurements; squares: uniform flow measurements; lines: Eq. (13)

relationship with $\beta$ is presented in Eqs. (16)-(17). In Fig. 12, the fitted $D_{u w}$ and $\lambda_{\text {uw }}$ from the measured data have respective regression coefficient $\mathrm{R}^{2}$ of 0.76 and 0.58 when compared to Eqs. (16)-(17).

$$
\begin{aligned}
& D_{u w}=0.03 \beta^{2}+0.24 \beta+1.42 \\
& \lambda_{u w}=-0.25 \beta^{2}-1.45 \beta+2.68
\end{aligned}
$$

Theoretically for uniform flow, the Reynolds stress near bed should be almost equal to $u_{*}^{2}$ where $\mathrm{D}_{\mathrm{uw}}=1$ (dotted line in Fig. 12a). From Fig. 12a, we can clearly observe that $\mathrm{D}_{\mathrm{uw}}$ remains around unity at the accelerating flow region (where $\beta<-1$ ), which shows a close resemblance to the uniform flow characteristic. At the decelerating flow region, stronger non-uniformity characteristic has been observed where all the measurements are higher than the uniform flow's $\mathrm{D}_{\mathrm{uw}}$. This finding suggests that the decelerating flow is more influential in determining the non-uniform characteristic for Reynolds stress compared to the accelerating flow. This suggestion is further supported by the fact that three different 

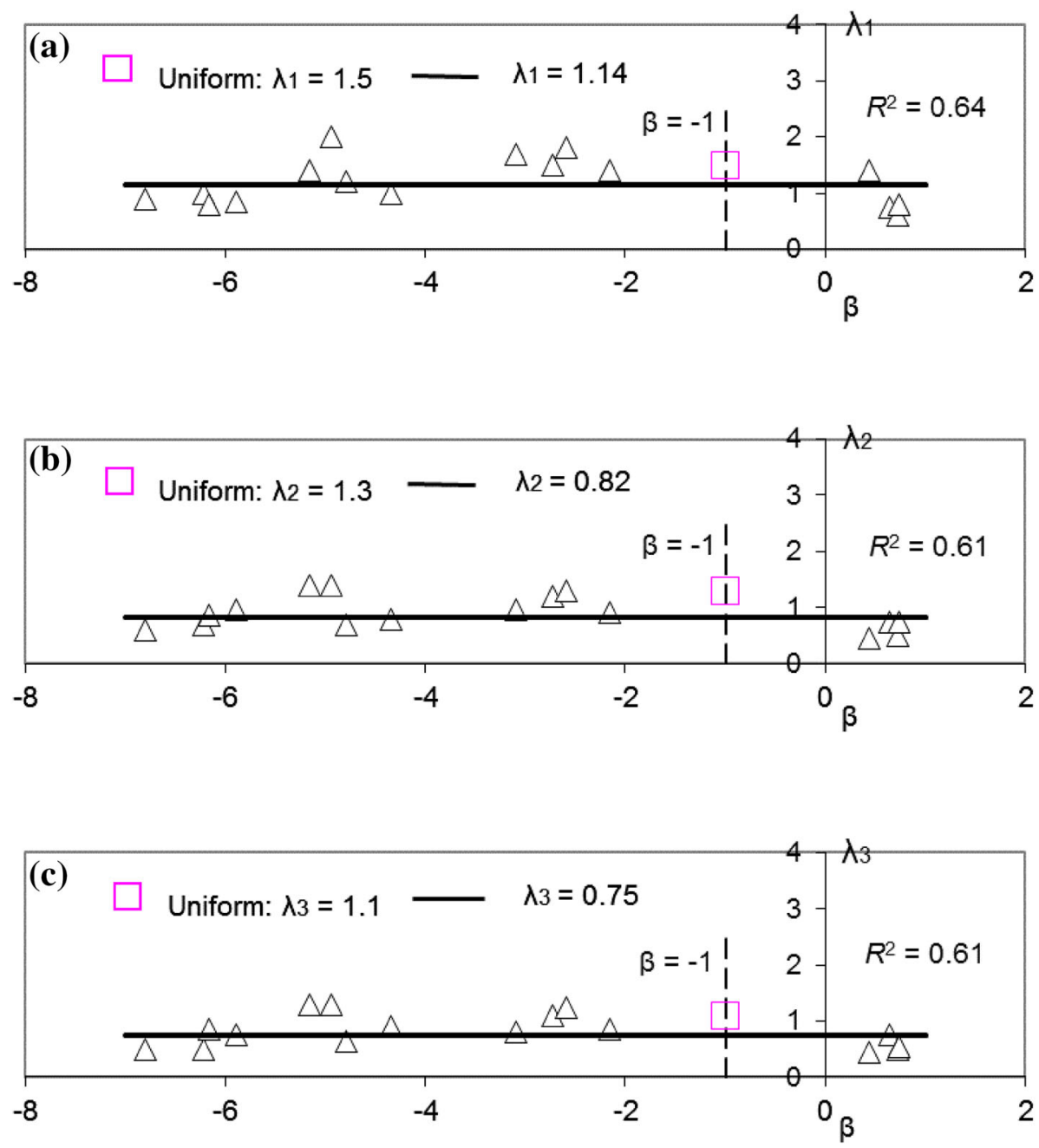

Fig. 11 Relationship of $\mathbf{a} \lambda_{1}$, b $\lambda_{2}$, and $\mathbf{c} \lambda_{3}$ with $\beta$ in Eqs. (10)-(12). Triangles: non-uniform flow measurements; squares: uniform flow measurements; lines: Eq. (14)

strengths of accelerating pressure gradients were tested in this study (from $\beta=-2.6$ to $\beta=-6.3$ ) and none of them give significant alteration to $D_{\mathrm{uw}}$ from uniform flow characteristic. In the full range of $\beta, D_{u w}$ shows a weak quadratic function suggesting its slow change across uniform and non-uniform flows. $\lambda_{\mathrm{uw}}$ is also found to be representable by a quadratic polynomial function with $\beta$ in Eq. (17). However, unlike $D_{u w}$ in Eq. (17), $\lambda_{\text {uw }}$ shows a stronger expression in $\beta^{2}$ proposing its fast change across uniform and nonuniform flows. The non-constant $\lambda_{\text {uw }}$ also displays different characteristic from the constant uniform flow's $\lambda_{1}, \lambda_{2}$ and $\lambda_{3}$.

As discussed above, by summarising the findings at Figs. 9, 10, 11 and 12 we can draw useful conclusions to the studied non-uniform flows. The insights gathered from these figures are also useful for hydraulic flow applications, such as flow through control structures which experiences rapidly varied flow between accelerating and decelerating 

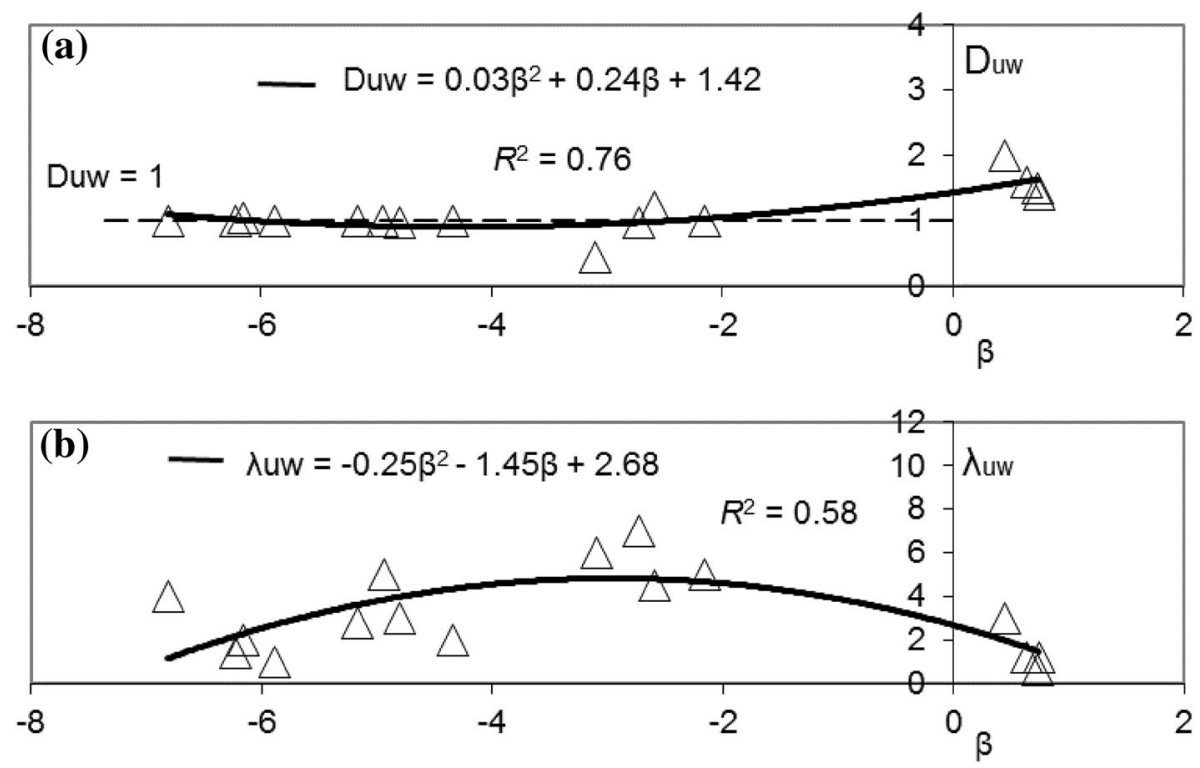

Fig. 12 Relationship of $\mathbf{a} D_{u w}$ and $\mathbf{b} \lambda_{\text {uw }}$ with $\beta$ in Eq. (15). Triangles: non-uniform flow measurements; lines: Eqs. (16)-(17)

features. For example, in flow phenomena passing weir or sluice, such as hydraulic jump or drop, sudden acceleration or deceleration in flow usually takes place. This rapid variation not only changes the flow characteristic but also affects other associated flow issues, i.e. sediment transport. Thus, a good understanding on accelerating and decelerating flows' characteristics and their dominance features can help in design such structures, i.e. in controlling the flow turbulence within these structures.

\section{Measurement limitations and cautions}

\subsection{Flow regime}

In present study, the main concentration is put on measuring the flow characteristics at centreline flow region. This is because when a flow is in 'wide' channel, i.e. with high width-to-flow-depth aspect ratio (b/h), velocity dip should not take place. This will cause the velocity and turbulence structure profiles to follow similar pattern regardless the measurements at centreline or region relatively nearer to sidewalls within the same longitudinal position.

There are several assumptions used in previous studies to describe the occurrence of velocity dip and the division between wide and narrow flows. Nezu and Nakagawa [19] described the $\mathrm{b} / \mathrm{h}$ ratio of $4.0-5.0$ as the threshold from narrow to wide open channel flow, where flow regime under this threshold limit can be impacted by velocity dip effect. However, studies focused on non-uniform flows, i.e. Graf and Song [8] and Song [27], found that for flows with and above aspect ratio of $\mathrm{b} / \mathrm{h}=3.5$, no velocity dip was recorded, which suggested they possessed a wide open-channel flow characteristic. Auel et al. [2] 
also described that strong velocity dip occurred up to $\mathrm{b} / \mathrm{h}<3$, and weak velocity dip can take place up to $\mathrm{b} / \mathrm{h}<5.0$.

In this study, flows with minimum aspect ratio of $\mathrm{b} / \mathrm{h}=3.57$ were tested. Our assumption for centreline data measurements was based on the tested aspect ratio would not cause dip phenomenon to the measured profile, which this assumption cannot be utilised if lower aspect ratio flows are going to be tested in any further work. In other words, if velocity dip caused by the secondary current from the side-walls takes place, then it can affect the measured data across channel width. For the flows with low aspect ratio, it will be essential to measure lateral flow profiles at various transverse locations within a longitudinal position to determine the effect from side-walls' secondary current.

\subsection{Flow non-uniformity}

This study presents five flow tests for uniform, accelerating and decelerating flows to analyse their velocity and turbulence structure profiles. The uniform flow characteristic is utilised to compare with the non-uniform flow findings, in order to validate the proposed relationships in this study (i.e. at Figs. 10, 11). The measured data in this study are also used to perform analysis to identify the key behaviour of accelerating and decelerating flows. However due to this wide research topic, further studies will be needed to test and identify the wider range of flow non-uniformity in order to further explore present study's findings. For example, more laboratory studies need to be conducted to provide more extreme non-uniform flow tests. More specifically, further tests with wider flow discharge and velocity ranges can create more extreme accelerating and decelerating flow conditions for advancing this study's flow tests. The added flow tests should also concentrate on supercritical flow condition to add on to the current obtained subcritical flow knowledge. Within a flow, the higher velocity increment (for accelerating flow) and decrement (for decelerating flow) can also be tested to identify the flow impacts from more extreme nonuniformity. In turns of the flow measurements, to obtain better accuracy convergence for time-averaged data, an ADV with higher sampling frequency power can be used for recording longer sampling time's data.

\section{Conclusions}

In this study, 3D turbulence characteristics of different accelerating and decelerating flows were investigated. Uniform flow test was also conducted for comparison to the nonuniform flows. The employed non-uniform flows measured a set of $\kappa, B_{r}$ and $\Pi$. $\kappa$ and $B_{r}$ for the non-uniform flows remained almost constant; while $\Pi$ was found to change in a linear relationship with the pressure gradient parameter $\beta$. Both $\kappa$ and $\mathrm{B}_{\mathrm{r}}$ constants found from this study corresponded to previous studies suggested range, in which $\kappa$ fell within the suggested range in Auel et al. [2] and $B_{r}$ showed similarity with the proposed values in rough bed flow studies by Kironoto and Graf [14] and Song and Chiew [28]. The $B_{r}$ finding further suggested its universality in different bed roughness conditions. The measured $\Pi$ was also found to correspond well to both smooth and rough bed flow formulae proposed by Nezu et al. [18] and Kironoto [12]; which suggested that $\Pi$ can be represented by universal rule for both rough and smooth bed non-uniform flows.

The experiments also showed that both non-uniform flow's 3D turbulence intensities and Reynolds stress were governed relatively well by exponential equations, where their 
exponential constants were well-described by quadratic functions in the investigated $\beta$ range. It was found that the decelerating flow showed higher turbulence intensity profile than the accelerating flow. For the accelerating flow tests, the normalised Reynolds stress distribution found to have similar magnitude (measured by coefficient $\mathrm{D}_{\mathrm{uw}}$ ) to the uniform flow; whereas this $\mathrm{D}_{\mathrm{uw}}$ magnitude was deviated in the decelerating flow. From the finding of non-uniform flows' turbulence intensity and Reynolds stress profiles, we can conclude that the decelerating flow has more dominant impact towards the flow's non-uniformity than the accelerating flow, due to its greater influence to alter the flow's turbulence structure. This has also been concluded from the comparison with the uniform flow profiles.

Acknowledgements The first and fourth authors acknowledge the support of the Major State Basic Research Development Grant No. 2013CB036402. The support from the Major State Basic Research Development Program (973 program) of China is also greatly appreciated. Comments and suggestions made by anonymous reviewers have greatly improve the quality of the manuscript.

Open Access This article is distributed under the terms of the Creative Commons Attribution 4.0 International License (http://creativecommons.org/licenses/by/4.0/), which permits unrestricted use, distribution, and reproduction in any medium, provided you give appropriate credit to the original author(s) and the source, provide a link to the Creative Commons license, and indicate if changes were made.

\section{References}

1. Anwar HO, Atkins R (1980) Turbulence measurements in simulated tidal flow. J Hydraul Div 106(8):1273-1289

2. Auel C, Albayrak I, Boes RM (2014) Turbulence characteristics in supercritical open channel flows: effects of Froude number and aspect ratio. J Hydraul Eng 140(4):04014004

3. Blanckaert K, Lemmin U (2006) Means of noise reduction in acoustic turbulence measurements. J Hydraul Res 44(1):1-15

4. Cardoso AH, Graf WH, Gust G (1989) Uniform flow in a smooth open channel. J Hydraul Res 27(5):603-616

5. Cardoso AH, Graf WH, Gust G (1991) Steady gradually accelerating flow in a smooth open channel. J Hydraul Res 29(4):525-543

6. Coles D (1956) The law of the wake in the turbulent boundary layer. J Fluid Mech 1(2):191-226

7. Dey S, Raikar RV (2007) Characteristics of loose rough boundary streams at near-threshold. J Hydraul Eng 133(3):288-304

8. Graf WH, Song T (1995) Bed-shear stress in non-uniform and unsteady open-channel flows. J Hydraul Res 33(5):699-704

9. Hoan NT, Booij R, Stive MJF, Verhagen HJ (2007) Decelerating open-channel flow in a gradual expansion. In: Proceedings of the fourth international conference on Asian and Pacific coasts, Nanjing, China, pp 902-915

10. Keulegan GH (1938) Laws of turbulent flow in open channels. J Res Natl Bur Stand 21:707-741

11. Kirkgoz MS (1989) Turbulent velocity profiles for smooth and rough open channel flow. J Hydraul Eng 115(11):1543-1561

12. Kironoto BA (1992) Turbulence characteristics of uniform and non-uniform, rough open-channel flow. $\mathrm{PhD}$ dissertation, École Polytechnique Fédérale De Lausanne, Swissland

13. Kironoto BA, Graf WH (1994) Turbulence characteristics in rough uniform open-channel flow. Proc Inst Civ Eng Water Marit Energy 106(4):333-344

14. Kironoto BA, Graf WH (1995) Turbulence characteristics in rough non-uniform open-channel flow. Proc Inst Civ Eng Water Marit Energy 112(4):336-348

15. Mellor GL, Gibson DM (1966) Equilibrium turbulent boundary layers. J Fluid Mech 24(2):225-253

16. Nezu I (1977) Turbulent structure in open channel flows. PhD dissertation, Department of Civil Engineering, Kyoto University, Japan. (in Japanese)

17. Nezu I, Azuma R (2004) Turbulence characteristics and interaction between particles and fluid in particle-laden open channel flows. J Hydraul Eng 130(10):988-1001 
18. Nezu I, Kadota A and Nakagawa H (1994) Turbulent structures in accelerating and decelerating openchannel flows with laser Doppler anemometers. In: Proceedings of ninth congress APD-IAHR, Singapore, pp 413-420

19. Nezu I, Nakagawa H (1993) Turbulent open-channel flows. IAHR monograph. A. A. Balkema, Rotterdam

20. Nezu I, Rodi W (1986) Open-channel flow measurements with a laser Doppler anemometer. J Hydraul Eng 112(5):335-355

21. Noguchi K, Nezu I (2009) Particle-turbulence interaction and local particle concentration in sedimentladen open-channel flows. J Hydro Environ Res 3:54-68

22. Onitsuka K, Akiyama J, Matsuoka S (2009) Prediction of velocity profiles and Reynolds stress distributions in turbulent open-channel flows with adverse pressure gradient. J Hydraul Res 47(1):58-65

23. Papanicolaou AN, Hilldale R (2002) Turbulence characteristics in gradual channel transition. J Hydraul Eng 128(9):948-960

24. Pu JH (2015) Turbulence modelling of shallow water flows using Kolmogorov approach. Comput Fluids 115:66-74

25. Pu JH, Shao S, Huang Y (2014) Numerical and experimental turbulence studies on shallow open channel flows. J Hydro Environ Res 8:9-19

26. Pu JH, Wei J, Huang Y (2017) Velocity distribution and 3D turbulence characteristic analysis for flow over water-worked rough bed. Water 9:668. https://doi.org/10.3390/w9090668

27. Song T (1994) Velocity and turbulence distribution in non-uniform and unsteady open-channel flow. $\mathrm{PhD}$ thesis, École Polytechnique Fédérale De Lausanne, Switzerland

28. Song T, Chiew YM (2001) Turbulence measurement in nonuniform open-channel flow using acoustics Doppler velocimeter (ADV). J Eng Mech 127(3):219-232

29. Song T, Graf WH (1996) Velocity and turbulence distribution in unsteady open-channel flows. J Hydraul Eng 122(3):141-154

30. Song T, Graf WH, Lemmin U (1994) Uniform flow in open channels with movable gravel bed. J Hydraul Res 32(6):149-173

31. Steffer PM, Rajaratnam N, Peterson AW (1985) LDA measurements in open channel. J Hydraul Eng 111(1):119-130

32. Yang SQ (2009) Velocity distribution and wake-law in gradually decelerating flows. J Hydraul Res 47(2):177-184

33. Yang SQ, Lee JW (2007) Reynolds shear stress distributions in a gradually varied flow in a roughened channel. J Hydraul Res 45(4):462-471

34. Yang SQ, Yu H, Dharmasiri N (2011) Flow resistance over fixed roughness elements. J Hydraul Res 49(2):257-262

35. Yu G, Tan SK (2006) Errors in bed shear stress as estimated from vertical velocity profile. J Irrig Drain Eng 132(5):490-497 